\title{
Preparation and Antibacterial Activity of Some New 4-(2-Heterylidenehydrazinyl)-7-chloroquinoline Derivatives
}

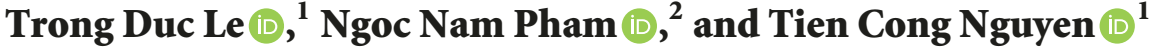 \\ ${ }^{1}$ Department of Chemistry, Ho Chi Minh City University of Education, Ho Chi Minh City 700000, Vietnam \\ ${ }^{2}$ Department of Organic Chemistry, Ho Chi Minh City University of Science, Vietnam National University, \\ Ho Chi Minh City 700000, Vietnam \\ Correspondence should be addressed to Tien Cong Nguyen; congnt@hcmup.edu.vn
}

Received 8 August 2017; Revised 30 October 2017; Accepted 7 November 2017; Published 15 January 2018

Academic Editor: Gabriel Navarrete-Vazquez

Copyright (C) 2018 Trong Duc Le et al. This is an open access article distributed under the Creative Commons Attribution License, which permits unrestricted use, distribution, and reproduction in any medium, provided the original work is properly cited.

\begin{abstract}
$N$-(4-Substituted phenyl)acetamides, which were prepared from acetic anhydride and $p$-substituted anilines, were utilized as precursors for reactions to Vilsmeier-Haack reagent to form 6-substituted-2-chloroquinoline-3-carbaldehydes 3a-c. Meanwhile, a similar reagent was applied to 1-[1-(4-substituted phenyl)ethylidene]-2-phenylhydrazines as substrates, which were synthesized from phenylhydrazine hydrochloride and $p$-substituted acetophenones, and 1,3-diarylpyrazole-4-carbaldehydes 3d-f were observed as a result. Reactions between the aldehydes $\mathbf{3 a - f}$ and 7-chloro-4-hydrazinylquinoline 2 , obtained from reaction of 4,7-dichloroquinoline 1 and hydrazine hydrate, formed six new hydrazone compounds, namely, 4-\{2-[(6-substituted-2chloroquinolin-3-yl)methylidene]hydrazinyl\}-7-chloroquinolines 4a-c and 4-(2-\{[3-(4-substituted phenyl)-1-phenyl-1H-pyrazol4-yl]methylene\}hydrazinyl)-7-chloroquinolines $\mathbf{4 d - f}$. The chemical structures of all synthesized compounds were elucidated by the analysis of IR, ${ }^{1} \mathrm{H},{ }^{13} \mathrm{C}$-NMR, and HRMS spectral data. Additionally, all of the synthesized hydrazones were evaluated in terms of cytotoxic activity against four strains of bacteria and four strains of fungus at several concentrations of substrates. As a result, three of them, $\mathbf{4 a}-\mathbf{c}$, possess the good ability as growth inhibitor of Bacillus subtilis and Aspergillus niger at the concentration of $25 \mu \mathrm{g} / \mathrm{mL}$ and $50 \mu \mathrm{g} / \mathrm{mL}$, respectively, while compound $4 \mathrm{e}$ only shows a cytotoxic activity against Aspergillus niger at the concentration of $25 \mu \mathrm{g} / \mathrm{mL}$.
\end{abstract}

\section{Introduction}

Quinoline derivatives, which widely occur in nature, especially alkaloids, have become an important skeleton in synthetic chemistry due to their variety of applications in medicinal, bioorganic, and industrial chemistry. Some hydrazone derivatives possessing a quinoline moiety have been well known as having a broad spectrum of biological activities such as antibacterial [1], anticancer [2], antitubercular [3-5], antifungal [6], anti-inflammatory [7], antimalarial $[8]$, and antimicrobial $[9,10]$. According to Ferreira et al. [11], hydrazone derivatives, which were prepared from the reaction of 7-chloro-4-hydrazinylquinoline and heteroaromatic aldehydes, showed a good antimycobacterial activity in comparison with some drugs such as ethambutol and rifampicin. Additionally, some hydrazones being born from 2-chloroquinoline-3-carbaldehyde possessed a moderate to good antibacterial activity against both Gram-positive and Gram-negative bacteria [12].

Besides, pyrazole derivatives have been of great interest in medicinal chemistry for their role as potent antiparasitic [13], antimicrobial [14], and antitumor agents [15]. (4Chlorophenyl)-[1-(4-nitrophenyl)-3-phenylpyrazol-4-ylmethylene]amine [13] compound possesses a good activity against $L$. infantum with IC50 of $12.4 \mu \mathrm{M}$ while 5-(3-isobutyl1-phenyl-1H-pyrazol-4-yl)-2-substituted-1,3,4-oxadiazoles [15] have an anticancer activity against breast and liver cell line with IC50 of around $2-7 \mu \mathrm{M}$ and $4-13 \mu \mathrm{M}$, respectively.

In this article, 7-chloro-4-hydrazinylquinoline $\mathbf{2}$ was prepared from the reaction of 4,7-dichloroquinoline 1 and hydrazine hydrate and then was utilized as the key intermediate material for the synthesis of some new 
hydrazones containing 2-chloroquinoline or pyrazole moiety. The new synthesized hydrazones including $4-\{2-[(6-$ substituted-2-chloroquinolin-3-yl)methylidene]hydrazinyl\}7-chloroquinoline 4a-c and 4-(2-\{[3-(4-substituted phenyl)1-phenyl-1H-pyrazol-4-yl]methylene\}hydrazinyl)-7-chloroquinoline $\mathbf{4 d - f}$ were evaluated for antimicrobial activities against eight kinds of microorganisms. The chemical structure of the hydrazones was elucidated by IR, NMR, and HRMS spectral analysis and their biological activities were reported for the first time.

\section{Materials and Methods}

All chemicals were purchased from Merck or Aldrich and solvents were commercial and were used without any further purification.

Melting points were determined with a Gallenkamp digital Melting-point apparatus 5A-6797 and were uncorrected.

The IR absorption spectra were scanned on Shimadzu FTIR 8400 S spectrum using potassium bromide $(\mathrm{KBr})$ pellets.

All the ${ }^{1} \mathrm{H},{ }^{13} \mathrm{C}$-NMR, HSQC, and HMBC spectra were recorded on a Bruker Advance $500 \mathrm{MHz}$ model spectrometer using DMSO- $d_{6}$ as solvents and internal standard. The spinspin coupling constants $(J)$ are given in Hz. Peak multiplicity is reported as $s$ (singlet), $d$ (doublet), $d d$ (double-doublet), $t$ (triplet), $q$ (quartet), $m$ (multiplet), and $b r$ (broad).

Mass spectrometric data were recorded on a micrOTOFQII Bruker.

Thin-layer chromatography (TLC) was performed on silica-gel sheets (silica gel 60 F254, Merck) and visualized in ultraviolet light $(254 \mathrm{~nm})$.

The synthesis of the hydrazones containing quinoline heterocycles was performed following the steps shown in Scheme 1.

2-Chloroquinoline-3-carbaldehydes $\mathbf{3 a}-\boldsymbol{c}$ were prepared according to the literature [16]. $p$-Substituted aniline was added to the solution of acetic anhydride in acetic acid, following by being refluxed in 2 hours. Consequently, cooling to room temperature and pouring into ice water were performed to collect $\mathrm{N}$-(4-substituted phenyl)acetamide derivatives, which then reacted to the mixture of dimethylformamide and phosphoryl chloride (Vilsmeier-Haack reagent) to form 2chloroquinoline-3-carbaldehyde derivatives $\mathbf{3 a - c}$.

1,3-Diarylpyrazole-4-carbaldehydes $3 \boldsymbol{d}-\boldsymbol{f}$ were prepared according to the literature [17]. Phenylhydrazine hydrochloride was slowly added to the mixture of $4^{\prime}$-substituted acetophenones and acetic acid in ethanol. The reaction mixture was stirred and then was poured into water to separate the product 1-(1-phenylethylidene)-2-phenylhydrazine, which was treated with Vilsmeier-Haack reagent at $80-90^{\circ} \mathrm{C}$ in 15 hours to form 1,3-diphenylpyrazole-4-carbaldehyde derivatives $\mathbf{3 d - f}$.

Preparation of 7-Chloro-4-hydrazinylquinoline 2. 4,7-Dichloroquinoline $(10 \mathrm{~g}, 5 \mathrm{mmol})$ was dissolved in ethanol $(20 \mathrm{~mL})$ in which hydrazine hydrate $(35 \mathrm{~mL}, 50 \mathrm{mmol}$ ) was slowly dropped. The reaction mixture was refluxed for 2 hours. Consequently, this mixture was cooled to room temperature and was kept overnight to separate the solid. The yellow precipitates were filtered and recrystallized from ethanol to give compound 2. Yield: $80 \%$; mp. $224-225^{\circ} \mathrm{C}$ (literature [1]: $\left.223-225^{\circ} \mathrm{C}\right)$. IR $\left(\nu, \mathrm{cm}^{-1}\right): 3255,3258\left(-\mathrm{NH}-\right.$ and $\left.-\mathrm{NH}_{2}\right), 3055$ $\left(\mathrm{Csp}{ }^{2}-\mathrm{H}\right), 2931\left(\mathrm{Csp} p^{3}-\mathrm{H}\right), 1600(\mathrm{C}=\mathrm{C})$ and $1566(\mathrm{C}=\mathrm{N}) ;{ }^{1} \mathrm{H}-$ NMR $\left(500 \mathrm{MHz}, \mathrm{DMSO}-d_{6}\right) \delta(\mathrm{ppm}), J(\mathrm{~Hz}): 8.60(1 \mathrm{H}, b r$, $>\mathrm{NH}), 8.39(1 \mathrm{H}, b r, \mathrm{Ar}-\mathrm{H}), 8.16(1 \mathrm{H}, d, J=9.0, \mathrm{Ar}-\mathrm{H}), 7.76(1 \mathrm{H}$, $s, \operatorname{Ar}-\mathrm{H}), 7.39\left(1 \mathrm{H}, d d, J_{1}=9.0, J_{2}=2.0, \mathrm{Ar}-\mathrm{H}\right), 6.87(1 \mathrm{H}, b r, \mathrm{Ar}-$ $\mathrm{H})$ and $4.45\left(2 \mathrm{H}, b r,-\mathrm{NH}_{2}\right) ;{ }^{13} \mathrm{C}-\mathrm{NMR}\left(125 \mathrm{MHz}, \mathrm{DMSO}-d_{6}\right)$ $\delta$ (ppm): 152.8, 151.8, 148.8, 133.2, 127.4, 123.8, 115.9 and 98.8 (S1-S3 from Supplementary materials).

Preparation of 4-(2-Heterylidenehydrazinyl)-7-chloroquinoline Compounds $4 \boldsymbol{a}-\boldsymbol{f}$. Appropriate 2-chloroquinoline-3carbaldehyde derivatives 3a-c or 1,3-diphenylpyrazole-4carbaldehyde derivatives $\mathbf{3 d}-\mathbf{f}$ ( $1 \mathrm{mmol}$ ) were dissolved in absolute ethanol $(10 \mathrm{~mL})$ with a few drops of glacial acetic acid. This mixture was stirred for 10 minutes and then compound $2(0.19 \mathrm{~g}, 1 \mathrm{mmol})$ was added in. The reaction mixture was refluxed for 3 hours. At the completion of reaction, the mixture was cooled to room temperature to separate the solid, which was filtered and recrystallized from suitable solvent to give products $\mathbf{4 a}-\mathbf{f}$, respectively.

All the synthesized hydrazones were evaluated to in terms of antimicrobial activities against microorganism. The method for these experiences was based on the literature $[18,19]$.

\section{Result and Discussion}

7-Chlorohydrazinylquinoline 2 was prepared from the reaction of 4,7-dichloroquinoline 1 and hydrazine hydrate. Its ${ }^{1} \mathrm{H}-$ NMR spectrum (S2 from Supplementary materials) showed two broad singlet signals of hydrazine group $\left(-\mathrm{NHNH}_{2}\right)$ at $\delta_{\mathrm{H}} 8.6$ and 4.5. Additionally, there were a doublet signal at $\delta_{\mathrm{H}}$ 8.16 with spin-spin coupling of $9.0 \mathrm{~Hz}$ attributed to $\mathbf{H} 5$ and a double-doublet signal at 7.39 attributed to H6. Meanwhile, $\mathbf{H 8}$ gave a singlet signal at $\delta_{\mathrm{H}} 7.76$. Two signals appearing at $\delta_{\mathrm{H}} 8.39$ and 6.87 were attributed to $\mathbf{H} 2$ and $\mathbf{H} 3$, respectively. Theoretically, $\mathbf{H} \mathbf{2}$ and $\mathbf{H} \mathbf{3}$ usually appear as doublet signals due to having spin-spin coupling together. However, in our case, the ring system may lead to them becoming hydroxylic protons, and, so, the broad signals were obtained.

Compound 2 was utilized as a precursor for preparation of six new hydrazones according to Scheme 1. The reaction of 4,7-dichloroquinoline $\mathbf{1}$ with hydrazine hydrate formed 7 -chlorohydrazinylquinoline 2 , which was treated by 2 -chloroquinoline-3-carbaldehyde derivatives 3a-c to form 4-\{2-[(6-substituted-2-chloroquinolin-3yl)methylidene]hydrazinyl\}-7-chloroquinoline compounds 4a-c. Meanwhile, 4-(2-\{[3-(4-substituted phenyl)-1-phenyl$1 \mathrm{H}$-pyrazol-4-yl]methylene\}hydrazinyl)-7-chloroquinoline compounds $4 \mathbf{d}-\mathbf{f}$ were produced by the reaction of compound $\mathbf{2}$ and 1,3-diphenylpyrazole-4-carbaldehyde derivatives $\mathbf{3 d}-\mathbf{f}$.

The reaction of $\mathbf{2}$ and some heteroaromatic $\mathbf{3 a}-\mathbf{f}$ occurred easily and may be observed clearly by both changing color of reaction solution and the appearance of precipitates in the progress of reaction. 
<smiles>[X]c1ccc2nc(Cl)c(/C=N/Nc3ccnc4cc(Cl)ccc34)cc2c1</smiles>

(1)<smiles>[Y]c1ccc(-c2nc(C=O)n(-c3ccccc3)n2)cc1</smiles><smiles>[Y]c1ccc(-c2nn(-c3ccccc3)cc2/C=N/Nc2ccnc3cc(Cl)ccc23)cc1</smiles>

$\mathrm{X}=\mathrm{H}(\mathbf{a}), \mathrm{CH}_{3}(\mathbf{b}), \mathrm{OC}_{2} \mathrm{H}_{5}(\mathbf{c})$

$\mathrm{Y}=\mathrm{H}(\mathbf{d}), \mathrm{Cl}(\mathbf{e}), \mathrm{NO}_{2}$ (f)

Scheme 1: Pathway for preparation of 4-(2-heterylidenehydrazinyl)-7-chloroquinoline derivatives.

TABLE 1: The physical properties and IR spectral data of the $\mathbf{4 a}-\mathbf{f}$ compounds.

\begin{tabular}{|c|c|c|c|c|c|c|c|c|}
\hline \multirow[b]{2}{*}{ Comp. } & \multirow[b]{2}{*}{ Structure } & \multirow[b]{2}{*}{$\mathrm{X}$ or $\mathrm{Y}$} & \multirow{2}{*}{$\begin{array}{c}\text { Solvent } \\
\text { recrystallized }\end{array}$} & \multirow{2}{*}{$\begin{array}{l}\mathrm{Mp} . \\
\left({ }^{\circ} \mathrm{C}\right)\end{array}$} & \multirow{2}{*}{$\begin{array}{l}\text { Yield } \\
(\%)\end{array}$} & \multicolumn{3}{|c|}{$v\left(\mathrm{~cm}^{-1}\right)$} \\
\hline & & & & & & $\mathrm{C}-\mathrm{H}$ & $\mathrm{NH}$ & $\begin{array}{l}\mathrm{C}=\mathrm{C} \\
\mathrm{C}=\mathrm{N}\end{array}$ \\
\hline $4 a$ & & $\mathrm{H}$ & DMF : $\mathrm{H}_{2} \mathrm{O}$ & 236 & 83 & 3055 & 3179 & $\begin{array}{c}1615 \\
1566\end{array}$ \\
\hline $4 b$ & & $\mathrm{CH}_{3}$ & DMF : $\mathrm{H}_{2} \mathrm{O}$ & 239 & 83 & $\begin{array}{l}2895 \\
3055\end{array}$ & 3179 & $\begin{array}{c}1615 \\
1566\end{array}$ \\
\hline $4 c$ & & OEt & $\mathrm{EtOH}$ & 239 & 81 & $\begin{array}{l}2978 \\
3040\end{array}$ & 3232 & $\begin{array}{l}1620 \\
1582\end{array}$ \\
\hline $4 d$ & & $\mathrm{H}$ & Dioxane : $\mathrm{H}_{2} \mathrm{O}$ & 236 & 84 & 3063 & 3256 & $\begin{array}{l}1651 \\
1582\end{array}$ \\
\hline $4 \mathrm{e}$ & & $\mathrm{Cl}$ & DMF : $\mathrm{H}_{2} \mathrm{O}$ & 233 & 85 & 3063 & 3241 & $\begin{array}{l}1613 \\
1575\end{array}$ \\
\hline $4 \mathrm{f}$ & & $\mathrm{NO}_{2}$ & Ac: $\mathrm{H}_{2} \mathrm{O}$ & 236 & 83 & 3060 & 3215 & $\begin{array}{l}1620 \\
1555\end{array}$ \\
\hline
\end{tabular}

More information can be found in Supplementary Materials.

In IR spectra, the specific vibration of amino group $\left(-\mathrm{NH}_{2}\right.$, double peak) at $3255-3258 \mathrm{~cm}^{-1}$ disappeared while the sharpness peak of $\mathrm{N}-\mathrm{H}$ bonds still appeared around $3200 \mathrm{~cm}^{-1}$; the stretching bands of the $\mathrm{C}=\mathrm{N}$ bonds were recognized at $1555-1582 \mathrm{~cm}^{-1}$. These data are similar to those of the 7-chloro-4-quinolinylhydrazone compounds described in literature [3].

The physical properties and IR spectral data of the $4 \mathbf{a}-\mathbf{f}$ compounds were presented in Table 1.

The structures of the hydrazones were further confirmed by the HRMS data. Molecular ion peaks in the mass spectra of the products were in conformity with desired molecular formulas of them (see Tables 2 and 3 ).
Both the ${ }^{1} \mathrm{H}-\mathrm{NMR}\left(500 \mathrm{MHz}\right.$, DMSO- $\left.d_{6}\right)$ and ${ }^{13} \mathrm{C}-\mathrm{NMR}$ $\left(125 \mathrm{MHz}, \mathrm{DMSO}-d_{6}\right)$ spectra of these compounds showed all of the signals matching with the expected structures. The ${ }^{1} \mathrm{H}$-NMR spectra of each of the compounds $4 \mathbf{a}-\mathbf{f}$ showed the singlet signals at $\delta_{\mathrm{H}} 8.51-8.83$ and 11.11-11.70, which were attributed to $-\mathrm{CH}=\mathrm{N}-(\mathrm{H} 13)$ and $-\mathrm{NH}-(\mathrm{H} 11)$, respectively. Furthermore, each of the ${ }^{13} \mathrm{C}$ spectra presented a signal around 136-139 ppm, which made cross peak with the signal of $\mathrm{H13}$ in the HSQC spectra and so it was attributed to $-\mathrm{CH}=\mathrm{N}-(\mathbf{C 1 3})$. Besides, singlet signal of the methyl group in molecule of $\mathbf{4 b}$ appeared at $2.54 \mathrm{ppm}$; the signals of the ethyl group in $\mathbf{4 c}$ were assigned as quartet at $4.21 \mathrm{ppm}(2 \mathrm{H}, \mathrm{J}$ $=7.0 \mathrm{~Hz})$ and triplet at $1.44 \mathrm{ppm}(3 \mathrm{H}, J=7.0 \mathrm{~Hz})$. The singlet at 


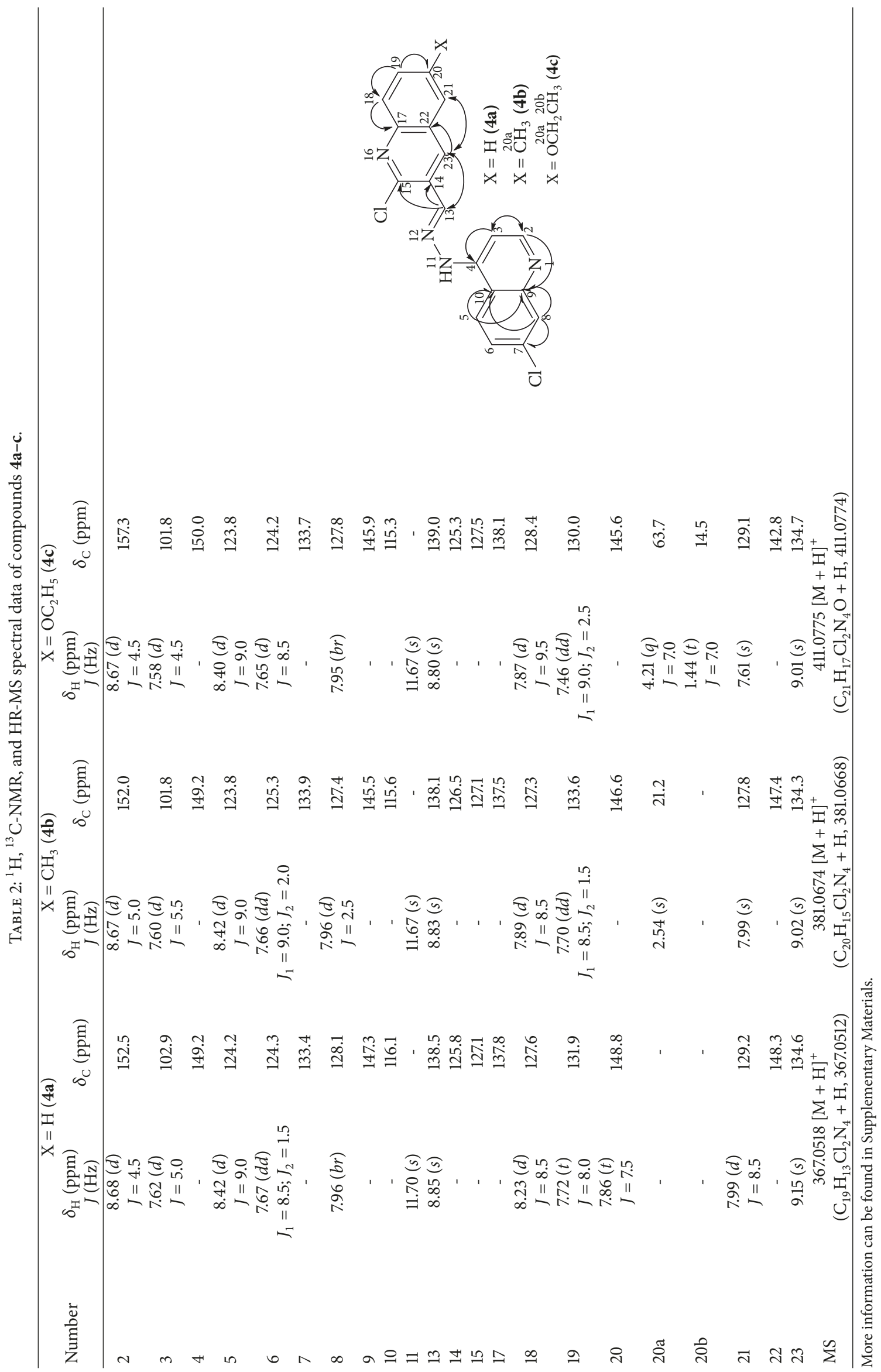




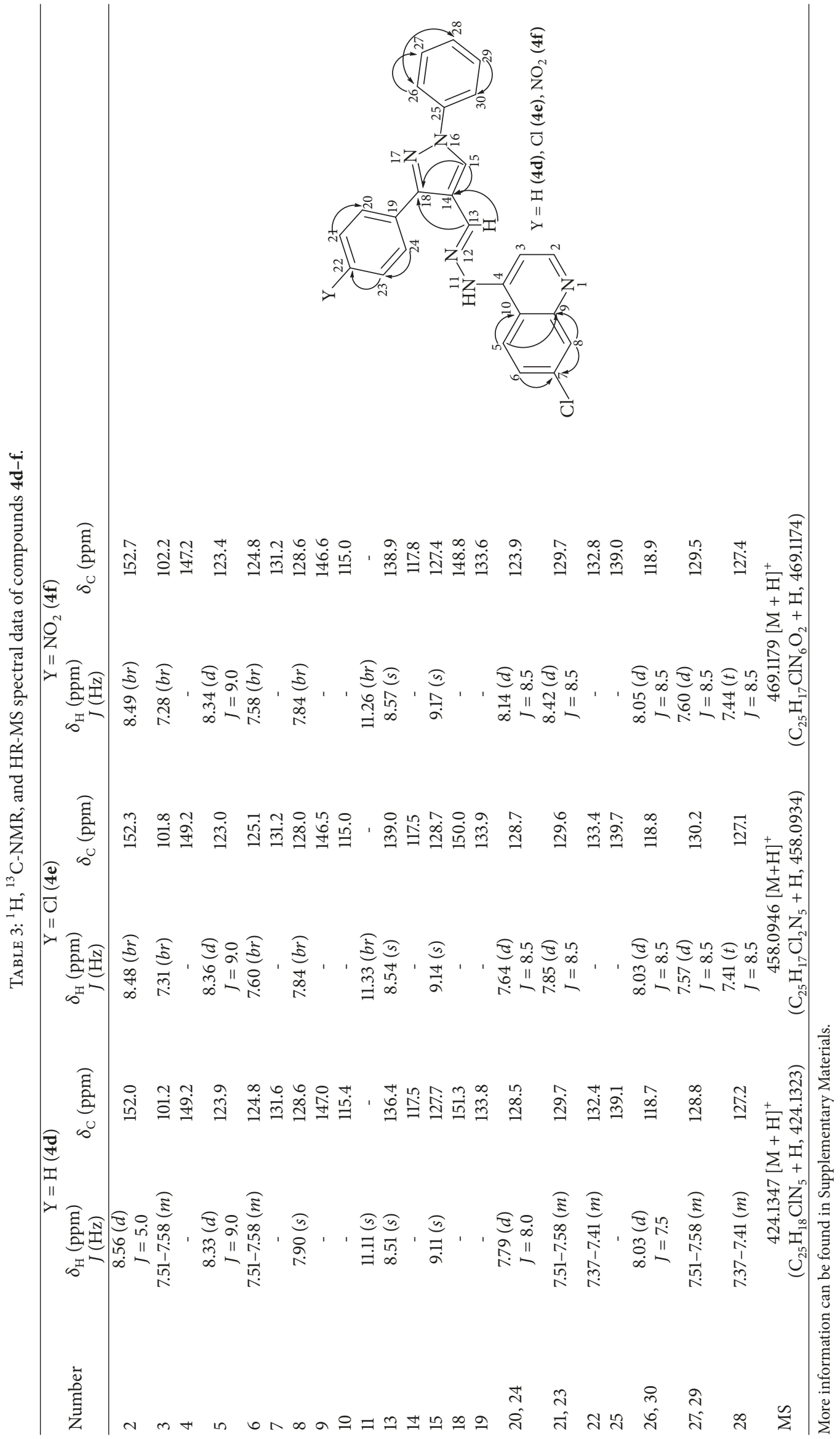


TABLE 4: Antimicrobial activity of hydrazones $\mathbf{4 a}-\mathbf{f}$.

\begin{tabular}{lllllllll}
\hline & \multicolumn{7}{c}{ Minimum inhibitory concentration (MIC: $\mu \mathrm{g} / \mathrm{mL}$ ) } \\
Samp. & \multicolumn{7}{c}{ Bacterial strains } & Fungal strains \\
& EC & PA & BS & SA & AN & FO & SC & CA \\
\hline $\mathbf{4 a}$ & $(-)$ & $(-)$ & 25 & $(-)$ & 50 & $(-)$ & $(-)$ & $(-)$ \\
$\mathbf{4 b}$ & $(-)$ & $(-)$ & 25 & $(-)$ & 50 & $(-)$ & $(-)$ & $(-)$ \\
$\mathbf{4 c}$ & $(-)$ & $(-)$ & 25 & $(-)$ & 50 & $(-)$ & $(-)$ & $(-)$ \\
$\mathbf{4 d}$ & $(-)$ & $(-)$ & $(-)$ & $(-)$ & $(-)$ & $(-)$ & $(-)$ & $(-)$ \\
$\mathbf{4}$ & $(-)$ & $(-)$ & $(-)$ & $(-)$ & $(-)$ & $(-)$ & $(-)$ & $(-)$ \\
$\mathbf{4 f}$ & $(-)$ & $(-)$ & $(-)$ & $(-)$ & 25 & $(-)$ & $(-)$ & $(-)$ \\
\hline
\end{tabular}

$(-)$ means negative; EC, PA, BS, and SA stand for Escherichia coli, Pseudomonas aeruginosa, Bacillus subtilis, and Staphylococcus aureus; AN, FO, SC, and CA stand for Aspergillus niger, Fusarium oxysporum, Saccharomyces cerevisiae, and Candida albicans.

$\delta_{\mathrm{H}} 9.01-9.15$ in the ${ }^{1} \mathrm{H}-\mathrm{NMR}$ spectra of compounds $4 \mathbf{a}-\mathbf{c}$ was assigned to proton in the 23th position (H23) while the singlet at $\delta_{\mathrm{H}}$ 9.11-9.17 in the ${ }^{1} \mathrm{H}-\mathrm{NMR}$ spectra of compounds $\mathbf{4 d - \mathbf { d }}$ was assigned to proton of the pyrazole ring (H15). A complete assignment of ${ }^{1} \mathrm{H}$ and ${ }^{13} \mathrm{C}$ NMR spectra of the hydrazones was based on analysis of NMR and 2D spectra (the HMBC correlations of $\mathbf{4 b}$ and $\mathbf{4 e}$ compounds were shown in the structures at Tables 2 and 3 ) and is presented in Tables 2 and 3.

The configuration of $-\mathrm{CH}=\mathrm{N}-$ bonds of hydrazone compounds was identified by their NOESY spectral analysis. The supposal configuration of compound $\mathbf{4 d}$ was $Z$ due to the correlation between $\mathbf{H} 2$ and $\mathbf{H 2 2} / \mathbf{2 8}$, which was shown in its NOESY spectrum. Meanwhile, the NOESY spectrum of compound $4 \mathbf{e}$ presented a cross peak of correlation of $\mathrm{H13}$ and H8, which confirmed the E configuration of this compound. There was a remark that the carbon signal of $-\mathrm{CH}=\mathrm{N}-$ group in $Z$ configuration appears at the higher magnetic field than in $E$ configuration [20]. In our case, the same observation was collected with the carbon signal of $-\mathrm{CH}=\mathrm{N}$ - group of compound $4 \mathbf{d}$ appearing at $\delta_{\mathrm{C}} 136.4$ whereas the others were collected at $\delta_{\mathrm{C}}$ 139.0. Furthermore, the ${ }^{13} \mathrm{C}$-NMR spectrum of compound $\mathbf{4} \mathbf{f}$ showed the signal of $-\mathrm{CH}=\mathrm{N}-$ group at $\delta_{\mathrm{C}} 138.9$, and, thus, its configuration was supposed to be $E$. These data were presented in Table 3.

All synthesized compounds were tested for antibacterial and antifungal activities. Four kinds of bacteria including Escherichia coli (ATCC 25922), Pseudomonas aeruginosa (ATCC 25923), Bacillus subtilis (ATCC 11774), and Staphylococcus aureus (ATCC 11632) and four fungus involving Aspergillus niger (439), Fusarium oxysporum (M42), Candida albicans (ATCC 7754), and Saccharomyces cerevisiae (SH 20) were utilized for these experiments. The results were presented in Table 4.

As the data has shown, the series of 7-chloro-4-[2(2-chloroquinolin-3-yl-methylene)hydrazinyl] quinoline compounds $4 \mathbf{a}-\mathbf{c}$ possess antibacterial and antifungal activities against Bacillus subtilis at the concentration of $25 \mu \mathrm{g} / \mathrm{mL}$ and Aspergillus niger at the concentration of $50 \mu \mathrm{g} / \mathrm{mL}$, respectively.

Meanwhile, in the other series, there was only 7-chloro4-(2-((3-(4-nitrophenyl)-1-phenyl-1H-pyrazol-4-yl)methylene)hydrazinyl)quinoline $4 \mathbf{f}$ showing the antifungal activity against Aspergillus niger at the concentration of $25 \mu \mathrm{g} / \mathrm{mL}$.

\section{Conclusion}

By a simple and convenient method, 7-chloro-4-hydrazinylquinoline 2 and six aldehydes including 2-chloro6-substituted quinoline-3-carbaldehydes $3 \mathbf{a}-\mathbf{c}$ and 1,3diarylpyrazole-4-carbaldehydes $\mathbf{3 d - f}$ were prepared. The reaction of hydrazine 2 with the heteroaromatic aldehydes 3a-f formed six new 4-(2-heterylidenehydrazinyl)-7chloroquinoline compounds $\mathbf{4 a}-\mathbf{f}$. Their chemical structures were elucidated by the analysis of IR, NMR, and HRMS spectral data. It was found that the configuration of hydrazones was $E$ except (Z)-4-\{2-[(1,3-diphenyl-1-phenyl$1 \mathrm{H}$-pyrazol-4-yl)methylene]hydrazinyl\}-7-chloroquinoline compound $4 \mathrm{~d}$. All of them were tested for the antimicrobial activities against eight kinds of bacteria and fungus. The results showed that the hydrazones containing 2chloroquinoline moiety $\mathbf{4 a - c}$ possess good activities in growth inhibition of Bacillus subtilis and Aspergillus niger at the concentration of 25 and $50 \mu \mathrm{g} / \mathrm{mL}$, respectively. In general, the hydrazones containing 1,3-diarylpyrazole moieties $\mathbf{4} \mathbf{d}-\mathbf{f}$ had been inactive but compound $\mathbf{4 f}$ exhibited high biological activity against Aspergillus niger at the concentration of $25 \mu \mathrm{g} / \mathrm{mL}$.

\section{Conflicts of Interest}

The authors declare that there are no conflicts of interest regarding the publication of this paper.

\section{Supplementary Materials}

Supplementary data associated with this article can be found in the attached file. These data include NMR $\left({ }^{1} \mathrm{H},{ }^{13} \mathrm{C}\right.$, HSQC, HMBC, and NOESY), IR, and HRMS spectra of the synthesized compounds $(\mathbf{2}, \mathbf{3} \mathbf{a}-\mathbf{f}, \mathbf{4 a}-\mathbf{f})$ : IR spectrum of compound (2); ${ }^{1} \mathrm{H}$ NMR spectrum of compound (2); ${ }^{13} \mathrm{C}$ NMR spectrum of compound (2); ${ }^{1} \mathrm{H}$ NMR spectrum of compound (3a); ${ }^{1} \mathrm{H}$ NMR spectrum of compound (3b); ${ }^{1} \mathrm{H}$ NMR spectrum of compound (3c); ${ }^{1} \mathrm{H}$ NMR spectrum of compound (3d); ${ }^{1} \mathrm{H}$ NMR spectrum of compound (3e); ${ }^{1} \mathrm{H}$ NMR spectrum of compound (3f); IR spectrum of compound (4a); ${ }^{1} \mathrm{H}$ NMR spectrum of compound (4a); ${ }^{13} \mathrm{C}$ NMR spectrum of compound (4a); HRMS spectrum of compound (4a); IR spectrum of compound (4b); ${ }^{1} \mathrm{H}$ 
NMR spectrum of compound (4b); ${ }^{13} \mathrm{C}$ NMR spectrum of compound (4b); HSQC spectrum of compound (4b); HMBC spectrum of compound (4b); NOESY spectrum of compound (4b); HRMS spectrum of compound (4b); IR spectrum of compound (4c); ${ }^{1} \mathrm{H}$ NMR spectrum of compound (4c);

${ }^{13} \mathrm{C}$ NMR spectrum of compound (4c); HRMS spectrum of compound (4c); IR spectrum of compound (4d); ${ }^{1} \mathrm{H}$ NMR spectrum of compound (4d); ${ }^{13} \mathrm{C}$ NMR spectrum of compound (4d); HRMS spectrum of compound (4d); NOESY spectrum of compound (4d); IR spectrum of compound (4e); ${ }^{1} \mathrm{H}$ NMR spectrum of compound (4e); ${ }^{13} \mathrm{C}$ NMR spectrum of compound (4e); HSQC spectrum of compound (4e); HMBC spectrum of compound (4e); NOESY spectrum of compound (4e); HRMS spectrum of compound (4e); IR spectrum of compound (4f); ${ }^{1} \mathrm{H}$ NMR spectrum of compound $(\mathbf{4 f}) ;{ }^{13} \mathrm{C}$ NMR spectrum of compound (4f); HRMS spectrum of compound (4f). (Supplementary Materials)

\section{References}

[1] N. H. Al-Sha'alan, "Antimicrobial activity and spectral, magnetic and thermal studies of some transition metal complexes of a Schiff base hydrazone containing a quinoline moiety," Molecules, vol. 12, no. 5, pp. 1080-1091, 2007.

[2] M. D. L. F. Bispo, C. C. De Alcantara, M. O. De Moraes et al., "A new and potent class of quinoline derivatives against cancer," Monatshefte für Chemie, vol. 146, no. 12, pp. 2041-2052, 2015.

[3] L. Savini, L. Chiasserini, A. Gaeta, and C. Pellerano, "Synthesis and anti-tubercular evaluation of 4-quinolylhydrazones," Bioorganic \& Medicinal Chemistry, vol. 10, no. 7, pp. 2193-2198, 2002.

[4] A. L. P. Candéa, M. D. L. Ferreira, K. C. Pais et al., "Synthesis and antitubercular activity of 7-chloro-4-quinolinylhydrazones derivatives," Bioorganic \& Medicinal Chemistry Letters, vol. 19, no. 22, pp. 6272-6274, 2009.

[5] S. Gemma, L. Savini, M. Altarelli et al., "Development of antitubercular compounds based on a 4-quinolylhydrazone scaffold. Further structure-activity relationship studies," Bioorganic \& Medicinal Chemistry, vol. 17, no. 16, pp. 6063-6072, 2009.

[6] A. R. Duval, P. H. Carvalho, M. C. Soares et al., "7Chloroquinolin-4-yl arylhydrazone derivatives: Synthesis and antifungal activity," The Scientific World Journal, vol. 11, pp. 1489-1495, 2011.

[7] Y.-L. Chen, I.-L. Chen, C.-M. Lu, C.-C. Tzeng, L.-T. Tsao, and J.-P. Wang, "Synthesis and anti-inflammatory evaluation of 4-anilinofuro[2,3-b] quinoline and 4-phenoxyfuro[2,3b]quinoline derivatives. Part 3," Bioorganic \& Medicinal Chemistry, vol. 12, no. 2, pp. 387-392, 2004.

[8] J. E. Charris, G. M. Lobo, J. Camacho et al., "Synthesis and antimalarial activity of (E) 2-(21-chloro-3/- quinolinylmethylidene)-5,7-dimethoxyindanones," Letters in Drug Design and Discovery, vol. 4, no. 1, pp. 49-54, 2007.

[9] S. T. Selvi, V. Nadaraj, S. Mohan, R. Sasi, and M. Hema, "Solvent free microwave synthesis and evaluation of antimicrobial activity of pyrimido[4,5-b]- and pyrazolo[3,4-b]quinolines," Bioorganic \& Medicinal Chemistry, vol. 14, no. 11, pp. 3896-3903, 2006.

[10] R. E. Khidre, A. A. Abu-Hashem, and M. El-Shazly, "Synthesis and anti-microbial activity of some 1- substituted amino-4,6dimethyl-2-oxo-pyridine-3-carbonitrile derivatives," European Journal of Medicinal Chemistry, vol. 46, no. 10, pp. 5057-5064, 2011.
[11] M. D. L. Ferreira, R. S. B. Gonçalves, L. N. D. F. Cardoso et al., "Synthesis and antitubercular activity of heteroaromatic isonicotinoyl and 7-chloro-4-quinolinyl hydrazone derivatives," The Scientific World Journal, vol. 10, pp. 1347-1355, 2010.

[12] S. Kumar, S. Drabu, R. Kumar, and S. Bawa, "Synthesis and antimicrobial activity of 2-chloro-6-methylquinoline hydrazone derivatives," Journal of Pharmacy and Bioallied Sciences, vol. 1, no. 1, pp. 27-31, 2009.

[13] P. Rathelot, N. Azas, H. El-Kashef et al., "1,3-Diphenylpyrazoles: Synthesis and antiparasitic activities of azomethine derivatives," European Journal of Medicinal Chemistry, vol. 37, no. 8, pp. 671679, 2002.

[14] R. Sridhar, P. T. Perumal, S. Etti et al., "Design, synthesis and anti-microbial activity of $1 \mathrm{H}$-pyrazole carboxylates," Bioorganic \& Medicinal Chemistry Letters, vol. 14, no. 24, pp. 6035-6040, 2004.

[15] M. A. Abu-Zaied, E. M. El-Telbani, G. H. Elgemeie, and G. A. M. Nawwar, "Synthesis and in vitro anti-tumor activity of new oxadiazole thioglycosides," European Journal of Medicinal Chemistry, vol. 46, no. 1, pp. 229-235, 2011.

[16] A. Srivastava and R. M. Singh, "Vilsmeier-Haack reagent: a facile synthesis of 2-chloro-3-formylquinolines from $\mathrm{N}$ arylacetamides and transformation into different functionalities," Indian Journal of Chemistry, vol. 44, no. 9, pp. 1868-1875, 2005.

[17] R. Dnyanpeeth, "Synthesis and pharmacological activities of 4carboxaldehyde and its aldimines derivatives," Asian Journal of Chemistry, vol. 20, no. 7, pp. 5037-5045, 2008.

[18] V. Bergher, "Screening methods for antibacterial and ativiral agent from higher plants," Methods in Plant Biochemistry. Academic Press in USA, vol. 6, 1991.

[19] L. Mckane and J. Kandel, Microbiology, McGraw-Hill, INC., 1996.

[20] A. R. Todeschini, A. L. P. de Miranda, K. C. M. da Silva, S. C. Parrini, and E. J. Barreiro, "Synthesis and evaluation of analgesic, antiinflammatory and antiplatelet properties of new 2-pyridylarylhydrazone derivatives," European Journal of Medicinal Chemistry, vol. 33, no. 3, pp. 189-199, 1998. 

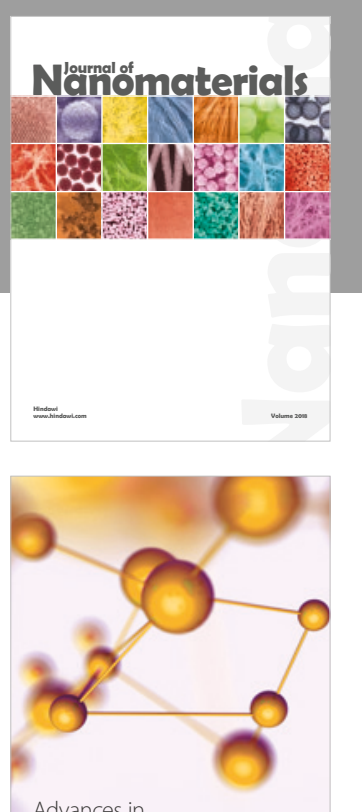

Physical Chemistry
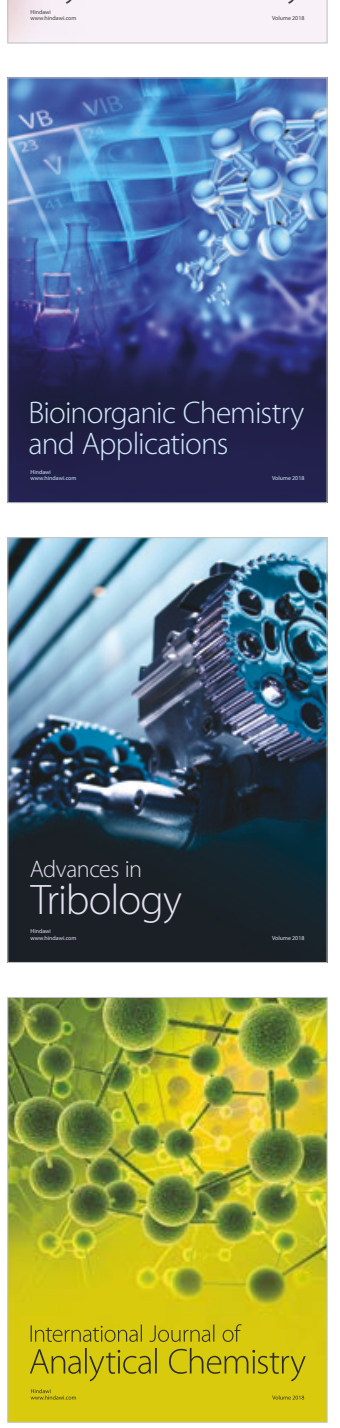

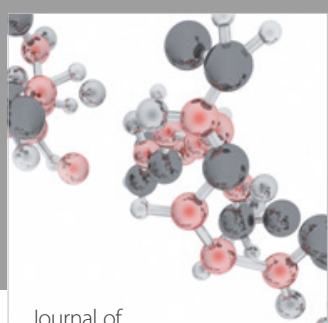

Analytical Methods

in Chemistry

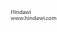

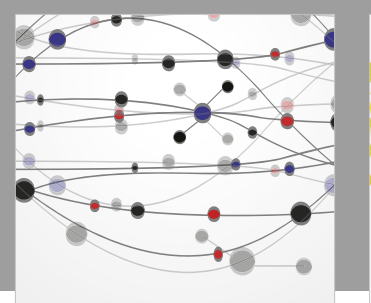

The Scientific World Journal

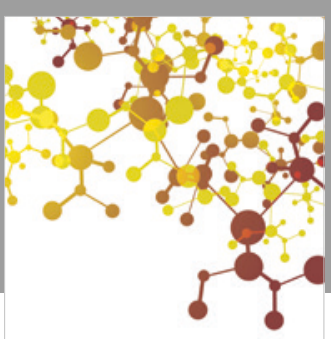

Journal of

Applied Chemistry
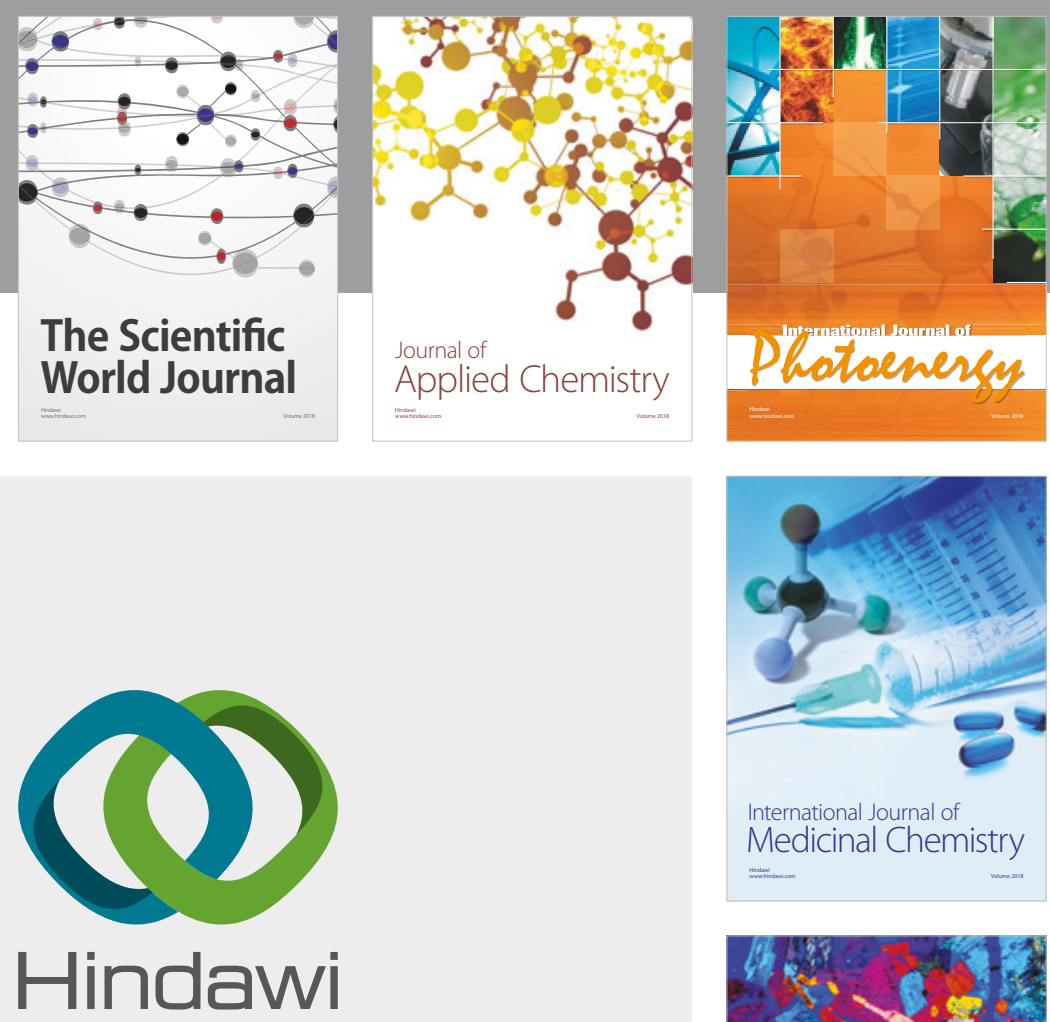

Submit your manuscripts at

www.hindawi.com
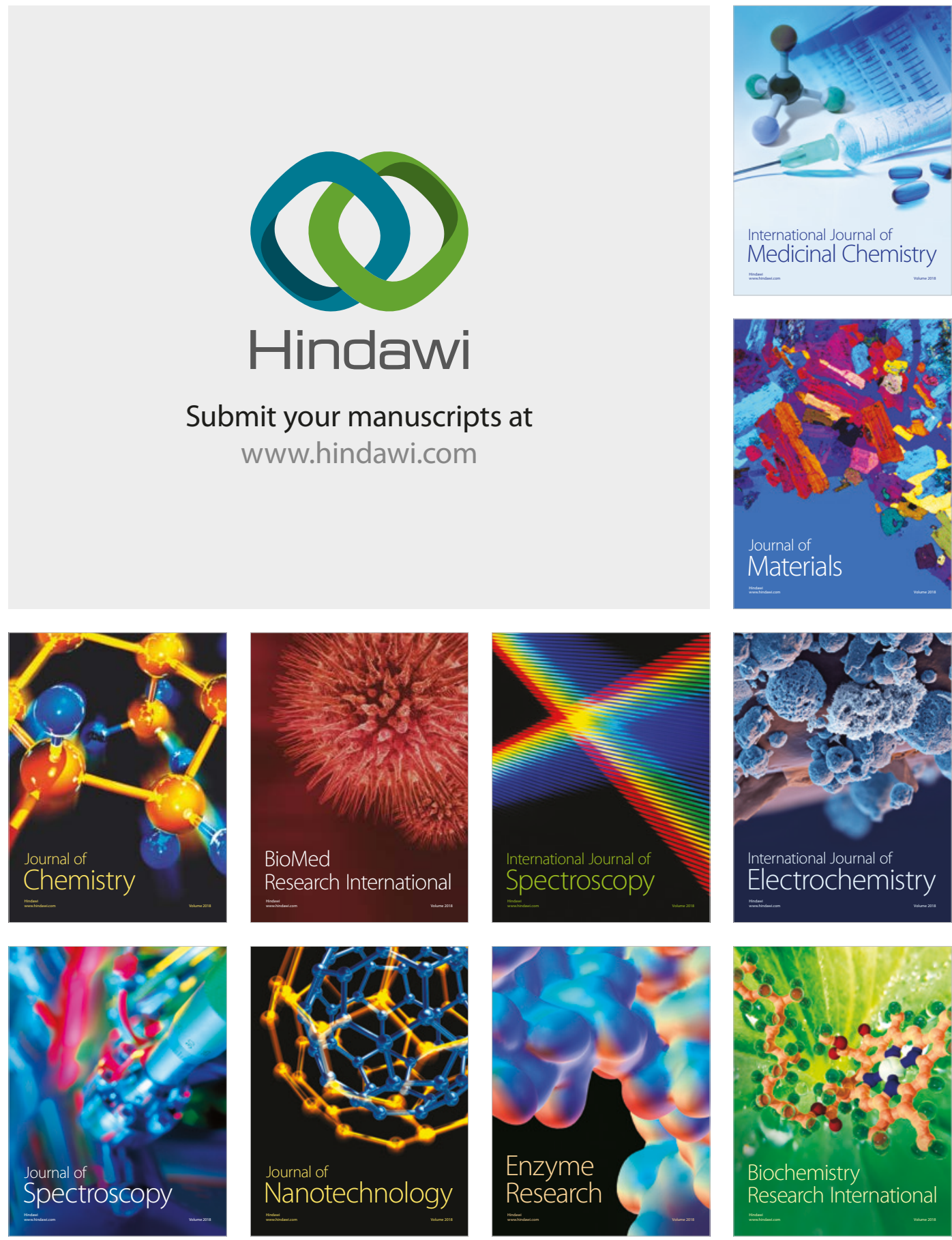
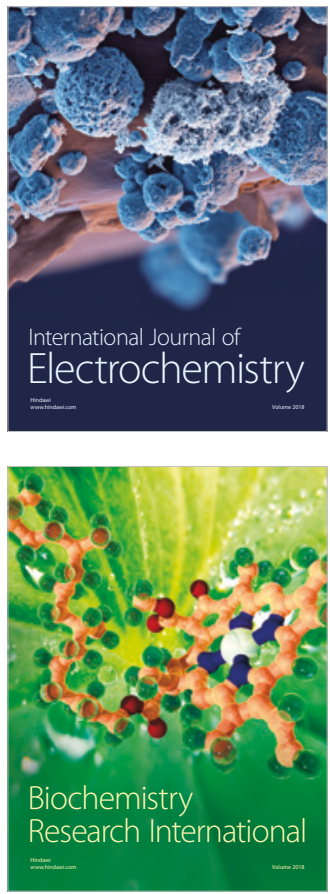